\title{
sciendo
}

\section{IMPROVING THE RABBIT SEMEN CRYOPRESERVATION PROTOCOL: COMPARISON BETWEEN TWO EXTENDERS AND INSEMINATING DOSES*}

\author{
Michele Di Iorio $^{1}$, Giusy Ruscoํ, Maria Antonietta Colonna ${ }^{2}$, Michele Schiavitto $^{3}$, \\ Mariasilvia D’Andrea ${ }^{1}$, Silvia Cerolini ${ }^{4}$, Nicolaia Iaffaldano ${ }^{1 *}$ \\ ${ }^{1}$ Department of Agricultural, Environmental and Food Sciences, University of Molise, \\ 86100 Campobasso, Italy \\ ${ }^{2}$ Department of Agricultural and Environmental Science, University of Bari Aldo Moro, 70126, \\ Bari, Italy \\ ${ }^{3}$ Italian National Rabbit Breeders (ANCI-AIA), 71030 Volturara Appula (Foggia), Italy \\ ${ }^{4}$ Department of Veterinary Medicine, University of Milan, 20134 Milan, Italy \\ •Corresponding author: nicolaia@unimol.it
}

\begin{abstract}
This study has been designed to optimize the semen freezing protocol in rabbits. In this regard we compared a Tris-citrate-glucose (TCG) extender with a commercial one (Cortalap ${ }^{\circledR}$ ), that to the best of our knowledge has never been used up to now on the in vitro freezability and fertilizing ability of cryopreserved rabbit semen. Two different inseminating semen doses were considered. Five pooled semen samples were divided into two subsamples and each of them were diluted to a ratio 1:1 (v:v) with a freezing extender composed of TCG or Cortalap ${ }^{\circledR}$ containing $16 \%$ of dimethylsulfoxide and $0.1 \mathrm{~mol} / \mathrm{L}$ of sucrose. The extended semen was filled into $0.25 \mathrm{~mL}$ plastic straws and frozen above a liquid nitrogen surface. After thawing $\left(50^{\circ} \mathrm{C} / 10\right.$ seconds $)$ we determined sperm motility, viability, membrane functionality, acrosome and DNA integrity. Our results showed that the Cortalap ${ }^{\circledR}$ extender significantly improved the in vitro post-thaw sperm quality, in comparison to TCG. When we compared the extenders in vivo, no significant differences in the reproductive performances were observed independently by inseminating doses used. In this study we demonstrated that Cortalap ${ }^{\circledR}$ extender can be used as an alternative to TCG. Thus, the Cortalap ${ }^{\circledR}$ being a ready to use extender, implies a reduction of time, mistakes and microbial contaminations during its preparation. This discovery is significant because it provides an important contribution to the creation of the first Italian semen cryobank of rabbit breeds and also for livestock rabbit farms based on artificial insemination (AI) program.
\end{abstract}

Key words: rabbit sperm, based extender, fertility, prolificacy, inseminating dose

*This research was funded by Cun-Fu project: "La cunicoltura del futuro: benessere e sostenibilità degli allevamenti cunicoli italiani”. National Rural Development Program (PSRN) 2014/2020. Characterization of animal genetic resources of zootechnical interest and protection of biodiversity. Submeasure: 10.2 . 
The role of rabbit breeds selected for meat production, has dramatically decreased (Jochová et al., 2017). This is due to the fact that the world production of rabbit meat is mainly based on commercial hybrid lines. According to the FAO guidelines (FAO, 2007) most rabbit breeds have been included in the national programs of genetic resources conservation. The value of these breeds has encouraged many conservation programs based on in situ and ex situ strategies at global and European levels. Even in Italy a conservation and valorisation project of Italian rabbit breeds is in progress thanks to the financial support of the Ministry of Agricultural, Food and Forestry Policies (MiPAAF). This project also involves the creation of the first Italian semen cryobank of rabbit breeds. In this regard, semen cryopreservation is a valuable tool for the conservation of animal biodiversity when it comes to facilitating the storage of gametes in a gene bank using thus the ex situ in vitro strategy (Blesbois, 2007; Leroy et al., 2011; Zaniboni et al., 2014; Iaffaldano et al., 2016).

Semen cryobank offers several benefits: allowing the backup of populations preserved in vivo in the event of genetic problems (inbreeding and genetic drift), therefore increasing the effective population size; providing the possibility to reconstruct breeds in the event of extinction or drastic reduction in the population. In this regard, the establishment of the semen cryobank assumes the identification of a reference procedure for rabbit semen cryopreservation.

Furthermore, the use of frozen semen could be advantageous, beyond safeguarding the rabbit breed biodiversity, but also for livestock rabbit farms based on artificial insemination (AI) program. To date, in rabbit farms AI is performed with fresh or cooled semen rather than frozen semen because of the poor fertility results after thawing (Mocé and Vicente, 2009; Lavara et al., 2017).

In our previous papers many variables of a rabbit semen freezing protocols have been studied (Iaffaldano et al., 2012, 2014; Kuliková et al., 2015; Di Iorio et al., 2018). Summing up the results obtained in the above mentioned works, we obtained the following best semen freezing protocol: cooling at $5^{\circ} \mathrm{C}$ for $90 \mathrm{~min}$, dilution $1: 1$ with the freezing extender (tris-citric acid-glucose - TCG) containing $16 \%$ of dimethylsulfoxide (DMSO) and $0.1 \mathrm{M}$ of sucrose, equilibration time of $45 \mathrm{~min}$ at $5^{\circ} \mathrm{C}$, exposure to liquid nitrogen vapour at $5 \mathrm{~cm}$ above the nitrogen. This protocol allowed us to reach similar reproductive performances with frozen semen to those recorded with fresh semen. The inseminating dose/straw $(0.25 \mathrm{~mL})$ contained a frozen sperm concentration ranging from 40 to $75 \times 10^{6} / \mathrm{mL}$ for each doe (Iaffaldano et al., 2012, 2104; Di Iorio et al., 2018).

So far, one of the parameters that we have not yet evaluated in the freezing protocol is the type of extender. In this regard, we have used Tris-based extender (TGC) in our previous research but it is also very frequently used in the world of rabbit sperm cryopreservation (Cortell and Viudes de Castro, 2008; Mocé and Vicente, 2009; Mocé et al., 2010, 2014; Hall et al., 2017; Zhu et al., 2015, 2017).

Here we are going to test the Cortalap ${ }^{\circledR}$, a commercial extender that would facilitate the semen freezing protocols. The choice of the Cortalap ${ }^{\circledR}$ is driven by the fact that in one of our previous studies it was the best among four extenders (Cortalap ${ }^{\circledR}$, TCG, Lepus ${ }^{\circledR}$ and Merk III ${ }^{\circledR}$ ), in terms of the in vitro preservability of rabbit spermatozoa stored for 72 hours at $5^{\circ} \mathrm{C}$ (Di Iorio et al., 2014). 
Up to now, to the best of our knowledge the Cortalap ${ }^{\circledR}$ has never been used in the cryopreservation protocol of rabbit semen. Therefore, this study has been designed to compare a commercial extender (Cortalap ${ }^{\circledR}$ ) with TCG on the in vitro freezability and in vivo reproductive performances of cryopreserved rabbit semen. Two different inseminating semen doses have been also considered.

\section{Material and methods}

\section{Chemicals}

All chemicals used were of the highest commercially available purity. Unless stated otherwise, all of the chemicals were purchased from Sigma Chemical Co. (Milan, Italy).

\section{Animals}

In this research 30 adult bucks ( 8 months old) and 150 does (8-9 months old) of the Bianca Italiana breed were used. Rabbits were kept at the Central Breeding Farm of Italian Rabbit Breeders Association (ANCI-AIA, Volturara Appula (FG), Italy). Animals were placed in individual flat-deck cages, subjected to a photoperiod of $16 \mathrm{~h}$ light/day, fed with commercial standard breeder diet and allowed free access to water. The experiments were carried out in accordance with the Code of Ethics of the EU Directive 2010/63/EU for animal experiments. The approval request number was 30003 of 20-12-2017 (2017-UNMLCLE-0030003).

\section{Semen collection and macroscopic evaluation}

Ejaculates were collected using a teaser doe and pre-heated artificial vagina. Only ejaculates that exhibited a white colour were used in the experiment, samples containing urine and/or cell debris were discarded, when present, gel plugs was removed. To be included in the study, ejaculates were required to be at least $400 \mu \mathrm{L}$ in volume. The ejaculates were pooled (4 ejaculates/pool) to avoid the effects of individual differences among males. In total, 5 pools were used for the experiments.

\section{Experiment 1. Effects of different extenders on post-thaw semen quality}

Semen pools were transferred from the farm to the laboratory in a polystyrene box at room temperature and within $30 \mathrm{~min}$. An aliquot was withdrawn from each pool to evaluate the fresh semen quality, as described below, and the remaining pooled semen was cooled at $5^{\circ} \mathrm{C}$ for 90 min before freezing (Di Iorio et al., 2018).

Subsequently, each pool was divided into two equal aliquots, and each of them was diluted to a ratio 1:1 (v:v) with a freezing extender composed of TCG $(250$ $\mathrm{mmol} / \mathrm{L}$ Tris-hydroxymethylaminomethane, $88 \mathrm{mmol} / \mathrm{L}$ citric acid, and $47 \mathrm{mmol} / \mathrm{L}$ glucose) or Cortalap ${ }^{\circledR}$ (IMV-Technologies), both extenders containing 16\% of DMSO (as permeating cryoprotectant) and $0.1 \mathrm{M}$ of sucrose (as non-permeating cryoprotectant). The extended semen was filled into $0.25 \mathrm{~mL}$ plastic straws and equilibrated 
at $5^{\circ} \mathrm{C}$ for $45 \mathrm{~min}$; in total, 200 straws were used $(20$ straws for each treatment $\times 2$ treatments $\times 5$ replicates). Then, the straws were allocated horizontally $5 \mathrm{~cm}$ above a liquid nitrogen surface for $10 \mathrm{~min}$ and plunged into liquid nitrogen for storage.

The straws were thawed after storage period of at least 1 month by transferring them into a water bath at $50^{\circ} \mathrm{C}$ for 10 seconds.

\section{Analysis of sperm quality variables}

The sperm quality parameters evaluated in both fresh and thawed semen were: sperm motility, viability, membrane functionality, and acrosome and DNA integrity. Moreover, for each pool of fresh semen the sperm concentration was evaluated using a Neubauer hemocytometer. Semen was diluted 1:100 (v:v) with 3\% $\mathrm{NaCl}$ (w:v) solution and spermatozoa were counted in the central grid of the hemacytometer. Both chambers of the hemocytometer were counted and averaged. Sperm concentration was expressed by million per milliliter (no. spz $\times 10^{6} / \mathrm{mL}$ ).

Sperm motility was evaluated by subjectively visual estimation. Briefly, $5 \mu \mathrm{L}$ of diluted semen $(1: 10$ in $\mathrm{NaCl} 0.9 \%)$ were delivered on a glass slide prewarmed at $37^{\circ} \mathrm{C}$ and covered with a coverslip. The slides were examined at $\times 400$ magnification using a phase-contrast microscope (Leica Aristoplan; Leitz Wetzlar, Heidelberg, Germany). At least five fields were observed and percentage of total motility (TM, spermatozoa showing any type of sperm head movement) and forward progressive motility (FPM, spermatozoa showing linear movement) were scored.

Sperm viability was estimated using two fluorescent stains SYBR-14 and propidium iodide (PI) (LIVE/DEAD Sperm Viability Kit-Molecular Probes, Inc.). This test was performed on $5 \mu \mathrm{L}$ of semen, which were added to $39 \mu \mathrm{L}$ of TCG containing $1 \mu \mathrm{L} \mathrm{SYBR}-14$ (diluted 1:100 in DMSO), incubated at $37^{\circ} \mathrm{C}$ for $10 \mathrm{~min}$, and then were added $5 \mu \mathrm{L}$ propidium iodide (diluted 1:100 in the TCG diluent) followed by incubation of a further $5 \mathrm{~min}$ at the same temperature. Lastly, $5 \mu \mathrm{L}$ of this solution were placed on microscope slides and examined at a magnification $\times 1000$ using a $\times 100$ oil immersion objective under epifluorescence illumination (blue excitation filter $\lambda=488 \mathrm{~nm}$ ). For each sample, minimum 200 sperm cells were counted in duplicate aliquots. Spermatozoa showing green fluorescence were marked as alive and those showing red fluorescence as dead. The percentage of viability was calculated as the number of green cells $\times 100$ divided by the total number of sperm counted.

The membrane functionality of the rabbit sperm was assessed by studying the swelling reaction of sperm tail when suspended in a medium of distilled water (hypoosmotic swelling test; HOST) as described by Lomeo and Giambersio (1991). This test is effective in measuring changes in sperm membrane functional status and permeability when exposed to hypo-osmotic conditions. The analysis was conducted by mixing $10 \mu \mathrm{L}$ of semen with $80 \mu \mathrm{L}$ of distilled water, incubating for $5 \mathrm{~min}$ at $37^{\circ} \mathrm{C}$, then $10 \mu \mathrm{L}$ were deposited on a clean glass slide and examined under a phasecontrast microscope (magnification $\times 400$ ). The typical sperm osmotic "coiled tail" reaction was easily detected, and the number of hypo-osmotic water test-positive cells was recorded by counting spermatozoa showing this feature among 200 cells examined (Rosato and Iaffaldano, 2011). 
Duplicate smears were realized using a drop of semen from each sample to evaluate acrosome integrity. After fixation in methanol for $30 \mathrm{~min}$, the slides were washed with water, air-dried and incubated with the Pisum sativum agglutinin FITC (fluorescein isothiocyanate) conjugate (FITC-PSA) for $30 \mathrm{~min}$ at room temperature (Mendoza et al., 1992). In each slide, assessment was made of 200 sperm at a magnification $\times 1000$ using an oil immersion objective under epifluorescence illumination. This stain intensely labels the acrosomal region of acrosome-intact sperm, which emit a uniform apple-green fluorescence, while acrosome-damaged spermatozoa show scarce or no green fluorescence in the anterior part of the head. The percentage of acrosome-intact spermatozoa was calculated as a fraction of the total.

Sperm DNA integrity was evaluated following the method developed by Gandini et al. (2006) using acridine orange (AO). Ten $\mu \mathrm{L}$ of semen were smeared onto a microscope slide, air-dried and fixed overnight in a 3:1 methanol:glacial acetic acid solution. Slides were then stained with an AO solution $(0.2 \mathrm{mg} / \mathrm{mL}$ in water $)$. After an incubation period of $5 \mathrm{~min}$ in the dark at room temperature each smear was observed using a fluorescence microscope with a $490 \mathrm{~nm}$ excitation light and $530 \mathrm{~nm}$ barrier filter. Nuclei in at least 200 spermatozoa per slide were examined and scored as green or yellow-orange-red fluorescing (intact DNA or damaged DNA, respectively) and the percentage of normal and abnormal chromatin condensation calculated.

Experiment 2. Comparing the in vivo reproductive performance of rabbit does inseminated with semen cryopreserved using TCG and Cortalap ${ }^{\circledR}$ and two different volumes of inseminating dose

In this experiment, we tested the efficacy of semen frozen in presence of TCG and Cortalap ${ }^{\circledR}$ (using two different inseminating doses) with fresh semen in an artificial insemination trial. In total 150 multiparous (31 days postpartum) receptive rabbit does were used, that were divided into five treatment groups (30 does for each group):

1) fresh semen (control group), each doe received a $0.5 \mathrm{~mL}$ dose of fresh semen diluted 1:10 with Cortalap ${ }^{\circledR}$ extender (approximately $35 \times 10^{6}$ sperm),

2) TCG/0.25 mL: each doe was inseminated with one straw of thawed semen (approximately $75 \times 10^{6}$ sperm),

3) $\mathrm{TCG} / 0.18 \mathrm{~mL}$ : each doe received $0.18 \mathrm{~mL}$ of thawed semen (approximately $55 \times 10^{6}$ sperm),

4) Cortalap ${ }^{\circledR} / 0.25 \mathrm{~mL}$ : each doe was inseminated with one straw of thawed semen (approximately $75 \times 10^{6}$ sperm),

5) Cortalap ${ }^{\circledR} / 0.18 \mathrm{~mL}$ : each doe received $0.18 \mathrm{~mL}$ of thawed semen (approximately $55 \times 10^{6}$ sperm).

All of the does underwent the following biostimulation protocol to synchronize their estrus: flushing, that is, increasing feed amount/doe from $180 \mathrm{~g} / \mathrm{day}$ to ad libitum (3 days before insemination), changing cages ( 3 days before insemination), and increasing the photoperiod from 16 to 24 hours of light ( 2 days before insemination). At the time of insemination, each female received an intramuscular injection of buserelin acetate to induce ovulation $(1 \mu \mathrm{g} / \mathrm{doe})$. 
Fertility (number of pregnant does/number of inseminations) was determined by abdominal palpation performed on each doe 17 days after artificial insemination. At parturition, the factors: kindling rate (number of does giving birth/number of inseminations), number of kits born (total born/kindling), and number of kits born alive (total live-born/kindling) were assessed.

\section{Statistical analysis}

Sperm quality (motility, viability, membrane functionality, acrosome and DNA integrity) and reproductive performances (fertility, kindling, prolificacy and kits born alive) data were compared among treatments by ANOVA, followed by Duncan's comparison test. All statistical tests were performed using the software package SPSS (SPSS 15.0 for Windows, 2006; SPSS, Chicago, IL, USA). Significance was set at $\mathrm{P} \leq 0.05$.

\section{Results}

\section{Effects of TCG and Cortalap ${ }^{\circledR}$ on in vitro post-thaw semen quality}

The average sperm concentration of fresh semen was $610 \pm 15 \times 10^{6}$ spermatozoa/ $\mathrm{mL}$. The results of fresh and post-thaw semen quality in terms of TM, FPM, viability, membrane functionality, acrosome and DNA integrity are provided from Figure 1 to Figure 6, respectively. Better values of all sperm parameters (except for DNA integrity) were obtained in fresh semen $(\mathrm{P} \leq 0.05)$ in respect to those cryopreserved, even if higher TM, FPM, viability, membrane functionality and acrosome integrity were recorded in semen cryopreserved in presence of $\operatorname{Cortalap}^{\circledR}(\mathrm{P} \leq 0.05)$.

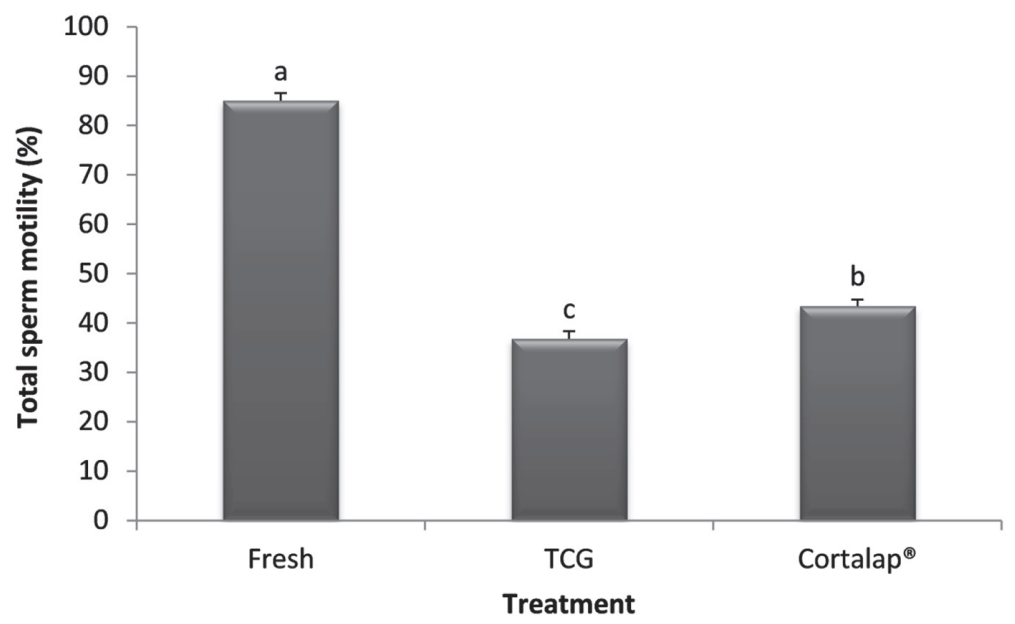

Figure 1. Total motility of fresh and frozen rabbit semen cryopreserved using TCG or Cortalap ${ }^{\circledR}$. Bars represent means \pm SEM. Different lowercase letters on bars indicate a significant difference $(\mathrm{P} \leq 0.05)$ 


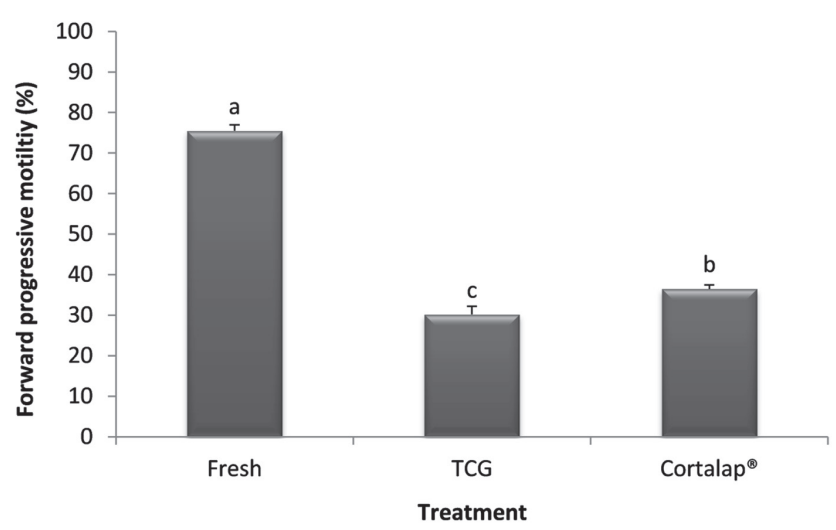

Figure 2. Forward progressive motility recorded in fresh and frozen rabbit semen cryopreserved using TCG or Cortalap ${ }^{\circledR}$. Bars represent means \pm SEM. Different lowercase letters on bars indicate a significant difference $(\mathrm{P} \leq 0.05)$

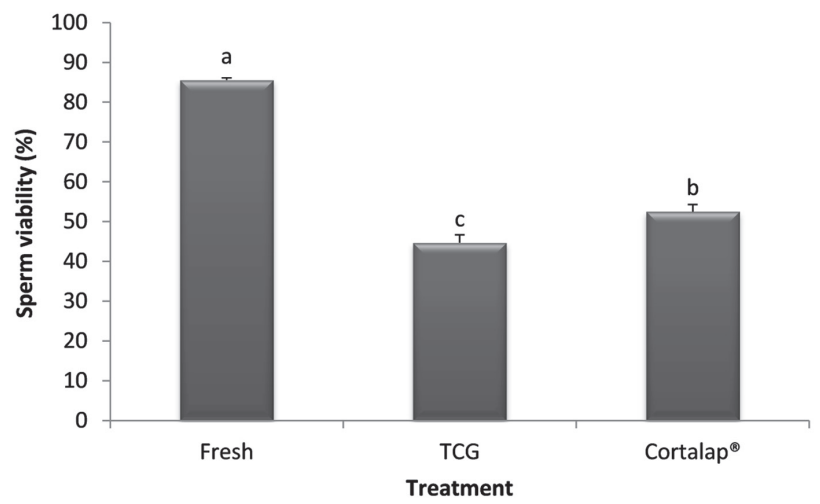

Figure 3. Sperm viability obtained in fresh and frozen rabbit semen cryopreserved in presence of TCG or Cortalap ${ }^{\circledR}$. Bars represent means \pm SEM. Different lowercase letters on bars indicate a significant difference $(\mathrm{P} \leq 0.05)$

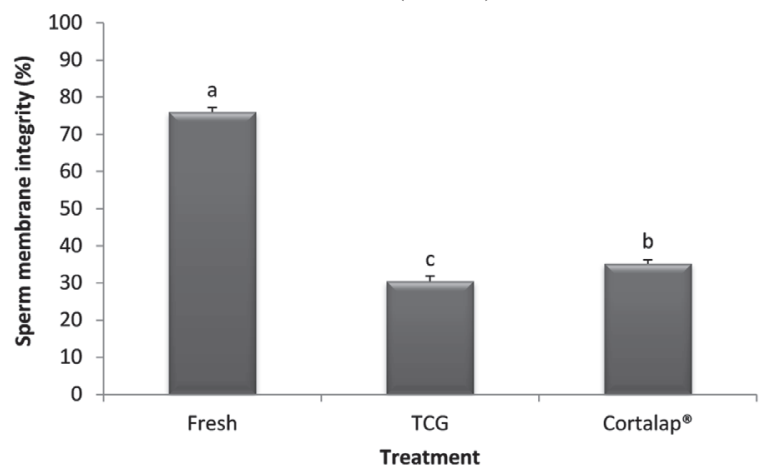

Figure 4. Sperm membrane functionality of fresh and frozen rabbit semen cryopreserved using TCG or Cortalap ${ }^{\circledast}$. Bars represent means \pm SEM. Different lowercase letters on bars indicate a significant difference $(\mathrm{P} \leq 0.05)$ 


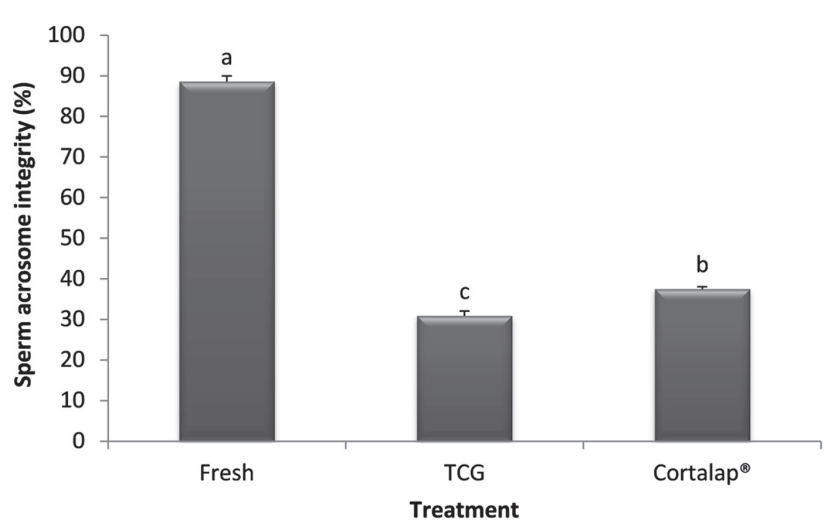

Figure 5. Acrosome integrity recorded in fresh and frozen rabbit semen, cryopreserved using TCG or Cortalap ${ }^{\circledR}$. Bars represent means \pm SEM. Different lowercase letters on bars indicate a significant difference $(\mathrm{P} \leq 0.05)$

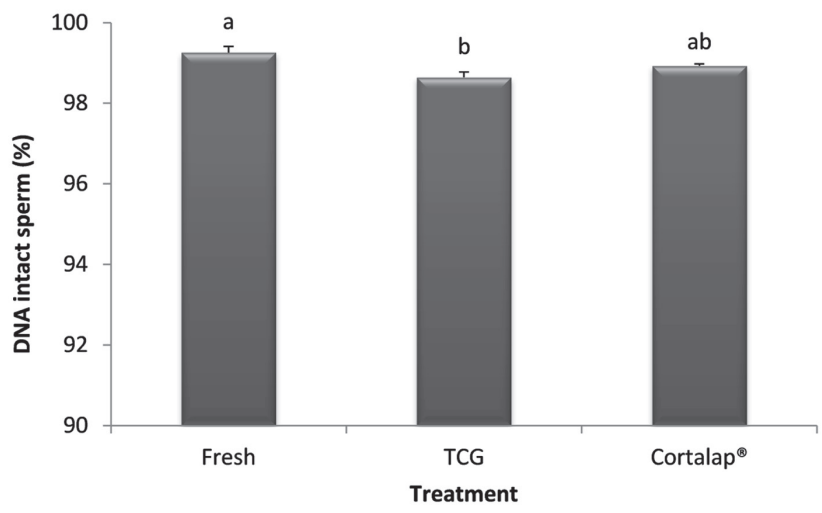

Figure 6. DNA integrity of fresh and frozen rabbit semen cryopreserved in presence of TCG or Cortalap $^{\circledR}$. Bars represent means \pm SEM. Different lowercase letters on bars indicate a significant difference $(\mathrm{P} \leq 0.05)$

\section{Artificial insemination}

Table 1 provides the reproductive performances recorded after the artificial insemination of does that were inseminated with fresh semen or semen frozen in presence of TCG or Cortalap ${ }^{\circledR}$.

No significant differences were observed for all reproductive performances considered among the treatments. Nevertheless, higher prolificacy and number of kits born alive were found in does fertilized with semen cryopreserved in presence of Cortalap $^{\circledast}(0.25 \mathrm{~mL})$; this based extender guarantees a higher number of total born and live born (197 and 183) compared with fresh semen (170 and 154) and semen frozen in TCG (178 and 170). 
Table 1. Reproductive performance outcomes in rabbit does after insemination with fresh semen or semen frozen in presence of TCG or Cortalap ${ }^{\circledR}$ considering two inseminating doses

\begin{tabular}{l|c|c|c|c|c|c}
\hline \multicolumn{3}{c|}{ Semen treatment } & \multicolumn{4}{c}{ Reproductive performances } \\
\hline & Extender & $\begin{array}{c}\text { Volume } \\
(\mathrm{mL})\end{array}$ & $\begin{array}{c}\% \text { Fertility } \\
(\mathrm{n})\end{array}$ & $\begin{array}{c}\text { \% Kindling } \\
(\mathrm{n})\end{array}$ & $\begin{array}{c}\text { Total born } \\
(\mathrm{mean} \pm \text { SEM })\end{array}$ & $\begin{array}{c}\text { Live born } \\
(\text { mean } \pm \text { SEM })\end{array}$ \\
\hline Fresh & & 0.5 & $80.0(24)$ & $73.3(22)$ & $7.7 \pm 0.7$ & $7.0 \pm 0.7$ \\
Frozen & TCG & 0.25 & $86.7(26)$ & $80.0(24)$ & $7.4 \pm 0.8$ & $7.1 \pm 0.8$ \\
& TCG & 0.18 & $73.3(22)$ & $70.0(21)$ & $7.8 \pm 0.5$ & $7.7 \pm 0.5$ \\
& Cortalap $^{\circledR}$ & 0.25 & $76.7(23)$ & $70.0(21)$ & $9.4 \pm 0.6$ & $8.4 \pm 0.9$ \\
& Cortalap $^{\circledR}$ & 0.18 & $70.0(21)$ & $63.3(19)$ & $8.4 \pm 0.9$ & $8.3 \pm 0.9$ \\
\hline
\end{tabular}

\section{Discussion}

The purpose of the present study was to evaluate the effect of Cortalap ${ }^{\circledR}$ that is a ready to use commercial extender that could substitute the TCG in freezing protocol of rabbit semen. Premising that the TCG, as a based extender turned out to be successful for rabbit sperm cryopreservation both by us and by other authors (Mocé and Vicente, 2009; Iaffaldano et al., 2012, 2014; Zhu et al., 2015, 2017; Hall et al., 2017; Di Iorio et al., 2018), the replacement of TCG with the Cortalap ${ }^{\circledR}$ could offer practical advantages such as: reduction of time, mistakes and microbial contaminations during its preparation. Thus, the Cortalap ${ }^{\circledR}$ that is a ready to use extender would facilitate the processing of the semen cryopreservation. Here, the Cortalap ${ }^{\circledR}$ has been tested for the first time for cryopreservation of rabbit semen and the rationale of its usage is based on the satisfactory results obtained previously in vitro in chilled semen (Di Iorio et al., 2014). Our results showed that the based extender clearly affected the post-thaw semen quality in vitro. In fact, the Cortalap ${ }^{\circledR}$ extender significantly improved sperm motility, viability, membrane functionality and acrosome integrity after the freezing process in comparison to TCG. Contrary to our expectations no significant differences were observed between the two extenders for all reproductive performances considered. This is consistent with Cortell and Viudes de Castro (2008) who observed similar reproductive performances between TCG and another commercial extender (MIII-Minitube).

We assume that the Cortalap ${ }^{\circledR}$ works similarly to TCG during the freezing of rabbit semen. Due to the commercial interests of the Cortalap ${ }^{\circledR}$ we were only able to know the type of component of extender which includes tris, citric acid, salts, sugars and water but not their concentrations. Some of these components are also present in the glucose-based Tris extender. However, an effective comparison between two extenders is difficult because we do not know what sugars are included and/or the concentrations of different components.

Notice that the role of extenders in semen preservation is primarily to extend the fertile life of sperm (indefinitely in the case of frozen semen) and to greatly extend the genetic potential of individual males through artificial insemination (A. I.) (Foote and Bratton, 1950). An extender must first meet the basic physiological requirements 
of sperm-iso-osmotic, near-neutral $\mathrm{pH}$ with an appropriate buffer and metabolizable substrate (Salamon and Maxwell, 2000; Layek et al., 2016). Therefore, an ideal extender should have nutrients as an energy source (glucose and fructose are most commonly used), substances that buffer against harmful changes of $\mathrm{pH}$, provide a physiological osmotic pressure and concentration of electrolytes (citric acid, sodium citrate, TES and Tris).

Thus, we can speculate that the Cortalap ${ }^{\circledR}$ extender provided a suitable condition for rabbit spermatozoa during cryopreservation process and preserved the in vitro spermatic characteristics of frozen semen better.

Another interesting point studied in this research was reducing the number of spermatozoa for each doe $\left(75 \times 10^{6} v s 55 \times 10^{6} \mathrm{sperm} /\right.$ female $)$ in order to fertilize a greater number of females using $0.18 \mathrm{~mL}\left(55 \times 10^{6} \mathrm{sperm}\right) /$ doe (in total $5.4 \mathrm{~mL} / 30$ female has been used). Although no significant differences were registered in the reproductive performances using two different inseminating volumes for both extenders, a decrease of about $10 \%$ of fertility and kindling rate was observed when the inseminating dose was $0.18 \mathrm{~mL}$. However, this information deserves attention in further research. Thus, at the moment we can sustain that the insemination dose corresponding to $55 \times 10^{6} \mathrm{sperm} /$ female turned out to be impractical during artificial insemination operations due to smaller volume dose used $(0.18 \mathrm{~mL})$.

Many studies have been performed to find out what the appropriate sperm dose is when using frozen semen for artificial insemination (Mocé and Vicente, 2009). Some authors worked at a fixed concentration of motile sperm ranging from 3 to $20 \times 10^{6}$ motile sperm/female (Maeda et al., 2012; Nishijima et al., 2015) while others implemented a fixed total sperm concentration (Arriola and Foote, 2001; Mocé et al., 2003 a, b, 2010; Viudes-de-Castro et al., 2005), or at a fixed semen dilution depending on the initial concentration of the ejaculates (Iaffaldano et al., 2012, 2014; Viudes-deCastro et al., 2014; Di Iorio et al., 2018).

However, the optimal number of frozen spermatozoa, in order to reach effective reproductive performances, is highly variable because it largely relates to the experimental conditions and the physiological status of the does at the moment of the insemination.

\section{Conclusions}

In conclusion the results obtained here provide a contribution to the development of an effective semen cryopreservation protocol that is necessary for the creation of the first rabbit cryobank that is an important milestone within our financed "MiPAAF" project which promotes the ex situ conservation strategies for the safeguard of rabbit breeds.

Moreover, the discoveries obtained here lay out the groundwork for further challenges. In this regard we aim to find an optimal sperm concentration for a straw utilizing commercial ready to use extender that ensures safety and facilitates to field activities such as the Cortalap ${ }^{\circledR}$.

\section{Conflict of interest}

The authors declare no conflicts of interest. 


\section{Acknowledgements}

The authors would like to thank the President (Dr. Sergio Pompa) of Italian Rabbit Breeders Association (ANCI-AIA) for allowing the use of the Central Breeding Farm.

\section{References}

A rri o l a J., F o o te R.H. (2001). Accessory sperm as an indication of fertilizing ability of rabbit spermatozoa frozen in egg yolk acetamide with detergent. J. Androl., 22: 458-463.

Blesbois E. (2007). Current status in avian semen cryopreservation. Worlds Poult. Sci. J., 63: 213-222.

Cortell C., Viudes de Castro M.P. (2008). Effect of gelatin addition to freezing extender on rabbit semen parameters and reproductive performance. In: 9th World Rabbit Congress, Xiccato, G. (ed.). pp. 327-332.

Di I orio M., Manchis i A., Rocco M., Chrenek P., I a ffa ldano N. (2014). Comparison of different extenders on the preservability of rabbit semen stored at $5^{\circ} \mathrm{C}$ for 72 hours. Ital. J Anim. Sci., 13: 710-714.

Di Iorio M., Colonna M.A., Miranda M.,Principe P., Schiavitto M., Manchisi A., I a ffa ld a no N. (2018). Initial cooling time before freezing affects post-thaw quality and reproductive performance of rabbit semen. Anim. Sci. J., 89: 1240-1244.

FAO (2007). The State of the World's Animal Genetic Resources for Food and Agriculture. Commission on Genetic Resources for Food and Agriculture. Food and Agriculture Organization of the United Nations, Rome, Italy.

F o o te R.H., B ratt o n R.W. (1950). The fertility of bovine semen in extenders containing sulfanilamide penicillin, streptomycin, and polymyxin. J. Dairy Sci., 33: 544-547.

G a nd in i L., L o m b a rd o F., L e n z i A., S p a n o M., D o nd e r o F. (2006). Cryopreservation and sperm DNA integrity. Cell Tissue Bank., 7: 91-98.

H all S.E., N e g u s C., J o h in ke D., B a th g a te R. (2017). Adjusting cryodiluent composition for improved post-thaw quality of rabbit spermatozoa. PLoS ONE, 12(4), e0175965.

I a ffa ld a no N., D i I or i o M., R os a to M.P. (2012). The cryoprotectant used, its concentration, and the equilibration time are critical for the successful cryopreservation of rabbit sperm: Dimethylacetamide versus dimethylsulfoxide. Theriogenology, 78: 1381-1389.

I a ffa ld a no N., D i I or i o M., R os a to M.P., Manch is i A. (2014). Cryopreservation of rabbit semen using non-permeable cryoprotectants: Effectiveness of different concentrations of low-density lipoproteins (LDL) from egg yolk versus egg yolk or sucrose. Anim. Reprod. Sci., 151: 220-228.

I a ffald an o N., Di Iorio M., Cerolini S., Manchisi A. (2016). Overview of turkey semen storage: focus on cryopreservation - a review. Ann. Anim. Sci., 16: 961-974.

Jochová M., Novák K., Kott T., Z deněk V., Majzlíka I., Tůmová E. (2017). Genetic characterization of Czech local rabbit breeds using microsatellite analysis. Livest. Sci., 201: 41-49.

Kuliková B., Di I orio M., Ku bovicova E., Kuželová L., I a ffald a no N., Chrenek P. (2015). The cryoprotective effect of Ficoll on the rabbit spermatozoa quality. Zygote, 23: 785-794.

L a var a R., M o cé E., B a s e $1 \mathrm{~g}$ a M., Vic en te J.S. (2017). Freezability genetics in rabbit semen. Theriogenology, 102: 54-58.

Laye k S.S., Mohan ty T.K., K u mares an A., P ark s J.E. (2016). Cryopreservation of bull semen: Evolution from egg yolk based to soybean based extenders. Anim. Reprod. Sci., 172: 1-9.

Le roy G., D anchin-Burge C., Verrier E. (2011). Impact of the use of cryobank samples in a selected cattle breed: a simulation study. Genet. Sel. Evol., 43: 36.

L o m e o A.M., G i a m b e r s i o A.M. (1991) 'Water-test': a simple method to assess sperm-membrane integrity. Int. J. Androl., 14: 278-282.

Maeda T., Liu E., Nishijima K., Tanaka M., Yamaguchi S., Morimoto M., Wata$\mathrm{n}$ abe T., F an J., Kit a j im a S. (2012). Effect of the primary cooling rate on the motility and fertility of frozen-thawed rabbit spermatozoa. World Rabbit Sci., 20: 65-70. 
Mendoza C., Correras A., Moos J., Tesarik J. (1992). Distinction between true acrosome reaction and degenerative acrosome loss by a one-step staining method using Pisum sativum agglutinin. J. Reprod. Infertil., 95: 755-763.

M o ć E., Vi c e n te J.S. (2009). Rabbit sperm cryopreservation: A review. Anim. Reprod. Sci., 110: $1-24$.

M o cé E., Lavara R., Vic en te J.S. (2003 a). Effect of an asynchrony between ovulation and insemination on the results obtained after insemination with fresh or frozen sperm in rabbits. Anim. Reprod. Sci., 75: 107-118.

Mocé E., Vicente J.S., Lavara R. (2003 b). Effect of freezing-thawing protocols on the performance of semen from three rabbit lines after artificial insemination. Theriogenology, 60: 115-123.

M o cé E., L a vara R., Vic e n t e J.S. (2010). Effect of cooling rate to $5^{\circ} \mathrm{C}$, straw size and farm on fertilizing ability of cryopreserved rabbit sperm. Reprod. Domest. Anim., 45: e1-e7.

Mocé E., B lanch E., Talaván A., Viudes de C a stro M.P. (2014). Reducing the time rabbit sperm are held at $5^{\circ} \mathrm{C}$ negatively affects their fertilizing ability after cryopreservation. Theriogenology, 82: 1049-1053.

Nishijima K., Kitajima S., Koshimoto C., Morimoto M., Watanabe T., Fan J., $\mathrm{M}$ a t s u d a Y. (2015). Motility and fertility of rabbit sperm cryopreserved using soybean lecithin as an alternative to egg yolk. Theriogenology, 84: 1172-1175.

R o s a t o M.P., I a ffald a n o N. (2011). Effect of chilling temperature on the long-term survival of rabbit spermatozoa held either in a tris based or a jellified extender. Reprod. Domest. Anim., 46: 301-308.

S a 1 a m o n S., M a x w e 11 W.M.C. (2000). Storage of ram semen. Anim. Reprod. Sci., 62: 77-111.

Viudes de Castro M.P., Mocé E., Vicente J.S., Marco-Jiménez F., Lavara R. (2005). In vitro evaluation of in vivo fertilizing ability of frozen rabbit semen. Reprod. Domest. Anim., 40: 136-140.

Viudes de Castro M.P., Lavara R., Safaa H.M., Marco-Jiménez F., Mehais e n G.M.K., Vi c e n t e J.S. (2014). Effect of freezing extender composition and male line on semen traits and reproductive performance in rabbits. Animal, 8: 765-770.

Zaniboni L., Cass inelli C., Mangiagalli M.G., Gliozzi T.M., Cerolini S. (2014). Pellet cryopreservation for chicken semen: effects of sperm working concentration, cryoprotectant concentration, and equilibration time during in vitro processing. Theriogenology, 82: 251-258.

Zhu Z., Fan X., Lv Y., Zhang N., F an C., Zhang P., Z eng W. (2015). Vitamin E analogue improves rabbit sperm quality during the process of cryopreservation through its antioxidative action. PLoS ONE, 10(12): e0145383.

Zhu Z., Ren Z., Fan X., Pan Y., L v S., Pan C., Le i A., Zeng W. (2017). Cysteine protects rabbit spermatozoa against reactive oxygen species-induced damages. PLoS ONE, 12(7): e0181110.

Received: 28 X 2019

Accepted: 14 II 2020 